\title{
CLINICAL DEPARTMENT
}

\author{
A CASE OF MYELOID CHLOROMA * \\ O. W. ROWE, M.D., AND F. J. HIRSCHBOECK, M.D. \\ DULUTH, MINN.
}

Cases of chloroma are sufficiently rare to warrant reports of individual cases, particularly if of the myeloid variety, as the literature shows they are of less frequent occurrence than the lymphatic form.

\section{REPORT OF CASE}

History.-K. F., a boy, aged 18 months, the youngest child of three, born of healthy American parents, breast fed, was always well, except for an intestinal indigestion with diarrhea at 10 months, a double otitis media at 14 months, and an acute digestive disturbance at 17 months due to indiscretions in diet.

Aug. 30, 1919, the child was brought to the Clinic because of extreme irritability, restlessness at night, puffiness about the eyes and a swelling which had appeared on the left side of the head between the eye and the ear. Examination showed in addition, an enlarged gland at the angle of the jaw on the left side. There was a slight digestive disturbance.

Sept. 11, 1919, the weight was $10,810 \mathrm{gm}$., with a ptosis of the lid on both sides (the right worse than the left). A tumor was also manifest for the first time on the glabella and over the right zygomatic process.

September 17 , the temperature was normal. The white blood count was 81,600 and the differential count showed 88 per cent. myeloblasts, myelocytes, micromyelocytes and degenerated forms, the remainder of the nucleated cells being a few nucleated red cells, small lymphocytes and polymorphonuclear neutrophils. The Wassermann was negative.

Urine: The urine was repeatedly negative.

At this time a diagnosis of myeloid chloroma was made, based on the blood findings and the tumor formations characteristically found on the calvarium.

Physical Examination.-Sept. 17, 1919. The tumors between the eyes and the ears on both sides have decreased in size somewhat; both softer than when last seen. On the left side it is 3 by $2.5 \mathrm{~cm}$. in size; slightly raised. The right side is a little more prominent, the swelling extending from the eye to the ear, about $3 \mathrm{~cm}$. in vertical diameter. Both eyes are bloodshot. The right eye nearly closed by the "drop" lid. Venules dilated on both sides. A tumor is also found in the right cheek, about the size of a walnut, and somewhat flattened in shape. Another is found on the left cheek, about the size of a hazelnut. There are no other tumors on the head aside from those mentioned. The skin shows ecchymotic spots on the left side of the abdomen; also an ecchymosis in the left cheek, $2 \mathrm{~cm}$. in diameter, said by the parents to have followed an injury; this, however, is doubtful. The abdomen is flaccid. The liver edge $5 \mathrm{~cm}$. below the margin of the ribs, in the right nipple line. The spleen is $2.5 \mathrm{~cm}$. below the margin of the ribs, in the left anterior axillary line. Weight, $11,335 \mathrm{gm}$. In the right inguinal region there was a group of enlarged lymph glands, collectively about the size of a pigeon's egg.

The day following the child had a convulsion, became comatose, and died. On this day another blood count was taken: 68,400 leukocytes, $2,800,000$ erythrocytes, and the hemoglobin 70 per cent.

* Received for publication, Nov. 8, 1921.

* From the Duluth Clinic. 


\section{NECROPSY FINDINGS}

The necropsy was performed, Sept. 18, 1919, five hours after death.

Macroscopic.-The body was that of a well nourished male infant, $75 \mathrm{~cm}$. in length and weighing $11,300 \mathrm{gm}$. The head circumference (fronto-occipital) measured $44 \mathrm{~cm}$., the abdominal $47 \mathrm{~cm}$., and the chest $47 \mathrm{~cm}$. The skin was pale and mottled and showed postmortem lividity over the posterior part of the thorax. Rigor mortis was present in moderate degree. The hair was scant and dry. The scalp showed a slight seborrhea sicca. The anterior fontanel was open. The eyelids were swollen and the conjunctivae showed injection and ecchymosis, which was more marked on the right.

There was a tumor over each zygoma, having a firm consistency and the size of a hazelnut; tumors, somewhat larger in size and of a softer consistency, were present in each cheek, anterior to the parotid glands. Similar tumor masses were aiso present in the right submaxillary and the right submental regions.

Abdomen: The subcuticular fat was of normal thickness, consistency and color. The peritoneum was smooth, moist and shining. There was no fluid in the abdominal cavity.

The liver was moderately enlarged, the anterior edge being $4 \mathrm{~cm}$. below the costal margin in the midclavicular line. On section it appeared normal in consistency and color. The gallbladder was somewhat thickened. The spleen measured 3 by 5 by $7.5 \mathrm{~cm}$., and on section showed a firm and fairly fibrous surface. There were numerous adhesions between the anterior surface of the stomach and the transverse colon. The omentum immediately around these adhesions was thickened and studded with numerous small nodules. The pancreas was normal in size, but had a consistency somewhat firmer than normal. The left kidney measured 3 by 4 by 4 by $8 \mathrm{~cm}$. The capsule stripped easily, revealing a smooth surface. On section there were found to be numerous small nodules, similar to those seen in the omentum, scattered through the kidney substance. There were also small circumscribed pus pockets in the medulla. The markings were fairly distinct. The right kidney was of the same size and on section revealed a marked pyonephrosis, which had obliterated some of the pyramids. Nodules and pus pockets, similar to those seen in the left kidney, were present in both the cortex and medulla. These varied in size from a pinhead to a hazelnut. The ureters were $1 \mathrm{~cm}$. in diameter and were thickened. Their external surfaces were studded with small nodular tumors. The mesentery was greatly thickened and freely studded with small nodules, the largest approximating the size of a hazelnut. The stomach, intestines and urinary bladder showed no changes.

Thorax: The costochondral articulations were not enlarged but on the inner surface of the right sixth rib near the costochondral articulation was a small tumor measuring 0.75 by 1 by $1 \mathrm{~cm}$. in size. There were no pleural adhesions and the lungs appeared to be normal macroscopically, except for a few airless areas. A large amount of turbid fluid, containing numerous white particles, was in the pericardial cavity. An irregular and lobulated tumor the size of a walnut, was found in the pericardium, extending upward from the diaphragmatic surface. The heart was normal in size and the valves were normal. The myocardium and epicardium contained innumerable small tumors, similar to those found in the kidneys.

Cranium: Section of the scalp showed the muscles to be pale. The scalp was easily removed except over the glabella, where a tumor, 1 by 2.5 by $2.5 \mathrm{~cm}$. in size, and involving the periosteum was found. The anterior fontanel was $2 \mathrm{~cm}$. in diameter. The dura was firmly adherent to the skull cap underneath the tumor and in this region the meninges were slightly thickened, and the brain injected. On section the brain substance appeared to be normal. The choroid plexus showed miliary tumors throughout. The spinal cord was negative.

Microscopic Study.-Microscopic sections of the tumors, taken from different parts of the body, show a more or less constant picture, varying somewhat, dependent on the character of the tissues infiltrated. 
Kidneys: The section shows an area of kidney tissue almost entirely replaced by masses of tumor cells. These masses do not have a sharp line of demarcation, as seen in carcinoma, and show no tendency to any definite arrangement, although here and there circular configurations or rows of cells might suggest attempt at aciniformation. The cells are supported by a delicate fibrous network. The cells are practically all mononuclear, varying somewhat in size, and having round, triangular or quadrangular contours. The nuclei are relatively large, occupying one third to one half of the cell area; they are rich in chromatin and deep staining. The cytoplasm takes a rather deep eosin stain. In certain areas cells show degenerative changes, as evidenced by nuclear disintegration. Blood vessels are difficult to identify and simply suggest spaces between the cells. The tubules and some of the glomeruli are atrophied to a slight degree.

Liver: Section shows small masses of tumor cells having the same histologic characteristics and invasive tendencies as those seen in the kidney section. Some of the cells, however, are larger and show evidence of karyolysis.

Heart: The muscle fibers are separated by masses of tumor cells, exactly similar to those described in the kidney section. The invasion of tumor cells is very extensive.

Lungs: Sections through the airless areas, described above, show some of the alveoli filled with serum; while others, especially around the relatively larger arterial branches, contain cells histologically similar to the tumor cells in the kidney. Some of these infiltrate the alveolar walls.

Sections of lymph glands and the tumor masses over the glabella and the zygomatic processes showed pictures exactly similar to those described in the kidney section.

\section{HISTORY AND REVIEW OF LITERATURE}

It has always been a mooted question as to whether chloroma and the acute leukemias are definitely related in their pathogenesis, and authorities have aligned themselves on one side or another.

The first description of a case in the literature is by Allen Burns, ${ }^{1}$ an American, in 1823. The name "chloroma," however, was first used by King, ${ }^{2}$ of Glasgow, in 1853, antedating by one year, Aran ${ }^{3}$ who is usually recognized as the author of the name. Aran himself recognized King as the first to use the term, but strangely enough, King does not mention the name "chloroma" in his paper, except in the title, which led Dock to infer that the name was known previous to the publication of King's article, at least in a conversational way. The first comprehensive study of the reported cases was in 1893 , by Dock, ${ }^{4}$ who collected seventeen cases including his own-but since then reports have been more frequent, and now more than 100 cases have been reported. All the early cases were considered to be of the lymphatic type, and it was not until the twentieth century that the myeloid type was described, when Roman ${ }^{5}$ first collected the cases in the literature corresponding to the latter type. A better understanding of hematopoietic function 1823.

1. Burns: Observations on the Surgical Anatomy of the Head and Neck.

2. King: London \& Edinburgh Monthly J. M. Sc. 17: (Aug.) 1853.

3. Aran: Arch. gén. de Méd., October, 1854.

4. Dock: Am. J. M. Sc. 106:211, 1893.

5. Roman: Beitr. z. path. Anat. u. z. allg. Path. 55:61. 
is probably the reason for this more frequent recognition of the presumably less frequent myeloid form, as since then the proportion of myeloid cases has been fairly large, leading to the assumption that these cases were previously unrecognized, just as we now know that acute myelogenous leukemia is more frequently present than is ordinarily supposed.

Cause and Symptoms with Differential Features.-The symptomatology of the acute leukemias and the chloromas is similar in nearly every regard. Lehndorff ${ }^{\circ}$ mentions the predilection of the tumor growths for the bones of the head and orbit in chloroma as a distinguishing feature of this condition. Practically all observers agree in this, and add as further differential points the distinctive color of the tumors postmortem, except in the fulminating cases. The course, clinical symptomatology, blood picture and termination, are the same. The consensus of opinion is that both are due to primary bone marrow disease, and that the infiltration into the tissues is more extensive in chloroma. The latter is more distinctly heterotopic, and its infiltration into heterotopic tissues is a characteristic. Threadgold ${ }^{\top}$ considers the infiltration of vessel walls and the surrounding connective tissue typical of chloroma, indicating a greater degree of malignancy.

The differentiation from acute leukemia is not the only obstacle in the diagnosis, as other conditions are frequently simulated. This is true of such clinical entities as lymphosarcoma, Hodgkin's disease, Sternberg's leukosarcomatosis, the so-called "nodular" leukemia and epinephroma. In contrast to lymphosarcoma and Hodgkin's disease, we have the distinctive blood picture, which in these two conditions is never so markedly altered. Gumbel ${ }^{8}$ mentions the more marked, regular disposition of the cells in sarcoma as another factor. In Hodgkin's disease there is a slower course, with the absence of involvement of the parenchymal organs of the body and the usually nearly normal blood picture. Of the allied sarcomatous conditions, the disease known as epinephroma simulates chloroma most closely. It is characterized by metastases about the head and face, but is primarily an affection of the suprarenal glands, and the blood picture is aleukemic. Differentiation between leukosarcomatosis, nodular leukemia and chloroma is more difficult, and they probably are all merely variants of acute leukemic processes. Differentiation is made increasingly difficult when we consider the fine lines drawn in the interpretation of the cells found in blood smears. The cell frequently predominating in these cases is the so-called "lymphoid" cell, which resembles very

6. Lehndorff: Jahrb. f. Kinderh. u. phys. Erziehung, July, 1910.

7. Treadgold: Quart. J. M. 1:239, 1908.

8. Gumbel: Virchows Arch. f. path. Anat. 171: 1903 
closely the large lymphocytes found in the normal blood. Pappenheim ${ }^{9}$ describes a cell of this type as the mother cell of all white blood cells. This cell is normally present in the foetus in the marrow of bone, the spleen, the liver and the lymph glands, but does not persist in adult life. He believes that in fetal life this cell has the power, probably through two varying factors, to develop either into a lymphocyte or a leukocyte.

Ward ${ }^{10}$ and other observers conclude that these large cells in the leukemic processes are a reversion to the primitive mother cell, which has this potentiality to form lymphocytes or myelocytes, according to the exciting factors predominating. This unknown factor is the agent which predetermines a myelogenous or a lymphatic type of acute leukemia. This is borne out by the fact that in myeloid chloroma or in acute myelogenous leukemia one finds all graduations from the mother cell to the myeloblast, the myelocyte and, finally, the adult polymorphonuclear cell. Ward claims that the considerations of the tissues affected in the pathology are inadequate grounds for classifying leukemias, as we know that obviously myeloid tissue may be found in the marrow, since these mother cells, by virtue of their presence in lymph glands, may, paradoxical as it may seem, form myelocytes, and in the bone marrow, lymphoyctes. Both sorts of tissue may be found in the tumors of chloroma, one or the other predominating. The clinical course and gross pathology of myeloid or lymphatic chloroma, as in acute leukemia, must, therefore, be solely made from the blood picture and from the microscopic sections of the tissue. When these large lymphoid cells are present in predominating numbers, one cannot conclude that the case is of the lymphatic type merely on account of this finding, and if myelocytes are present to any degree, the diagnosis of the myeloid form of leukemia is proper. The more forcible the stimulus to overproduction of the cells, the more primitive the cell type, and the more difficult the differentiation. We have an analogous response in the erythroblastic formation, produced by varying degrees of hemolysis. Likewise, in carcinoma, at times the parent tissue is reproduced, whereas in more rapidly growing epitheliomas the character of the cells may be of an indifferent type. It must be borne in mind, however, that acute cases, from the beginning, are, during their course, always permanently lymphocytic or myelocytic, and a metamorphosis of the cells does not take place after the process has once begun. In the more slowly progressive cases, the differentiation is less difficult, and aside from the blood findings, sections of the spleen frequently show myeloid cells in the splenic pulp, definitely displacing the lymph adenoid tissue of the malpighian corpuscles.

9. Pappenheim: Folia Hematol., 1904-1909.

10. Ward: Proc. Roy. Soc. Med., Lond. 7: 1914. 
The Winkler-Schultz oxidase reaction is positive in these myeloid cases. Figure 1 shows clearly the predominating type of cells, distinctly myelocytic. Other cells, without granules, are present, undoubtedly myeloblasts and presumably lymphoid cells. The small number of adult cells, both lymphocytic and polymorphonuclear, is striking.

The blood picture in chloroma simulates or is identical with that of acute leukemia. Erythrocytes are oftentimes materially reduced, so that we may have less than one million per cubic millimeter. The hemoglobin is correspondingly reduced. The leukocytes vary in number from a leukopenia, as in Lehndorff's ${ }^{6}$ case, he reporting only 5,100 , to counts of 300,000 or more per c.m. The acuteness of the process

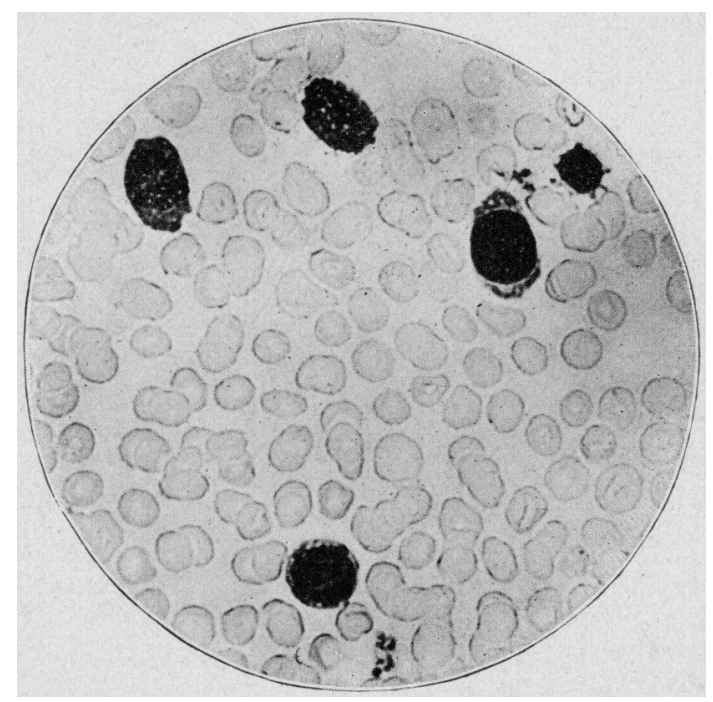

Fig. 1.-Photomicrograph of the blood smear, showing the myelocytes under high magnification.

usually may be identified by the incidence of the large lymphoid cells. The percentage of myelocytes in our case is unusually large. Turk ${ }^{11}$ reported 44 per cent. myelocytes, whereas ours showed 77 per cent.

A feature in our case not definitely explicable is the preponderance of myelocytes over the large, indeterminate lymphoid cells, in view of the fact that our patient lived only four weeks-a more rapid course than we have noted in any case previously reported.

Aside from the pathogenesis of the disease, another interesting feature is the green color which is almost invariably found in the chloromatous tumors. Quite a few cases, however, have been reported, in which this green color was not present ; for example, those of Birk, ${ }^{12}$

11. Turk: Wien. klin. Wchnschr., 1902.

12. Birk: St. Petersh. med. Wchnschr. 7:377, 1883. 
Leber, ${ }^{13}$ Wende, ${ }^{14}$ Miller ${ }^{15}$ and ours. Observers have noticed that the more fulminating the case the less apt the green color is to be present. As an example, Miller's case is cited, the patient living only three months. Our case ran its course in one-third that time. Furthermore, the green color is oftentimes absent in many of the tumors, and greenish discoloration has been noticed in lymphatic tuberculosis and in ordinary leukemias. The cause of the color is unknown. The color usually does not appear except postmortem, but has been seen at operation. Paviot ${ }^{16}$ discovered that the color spontaneously fades on exposure to the air, and reappears when treated with ammonia or peroxide of hydrogen.

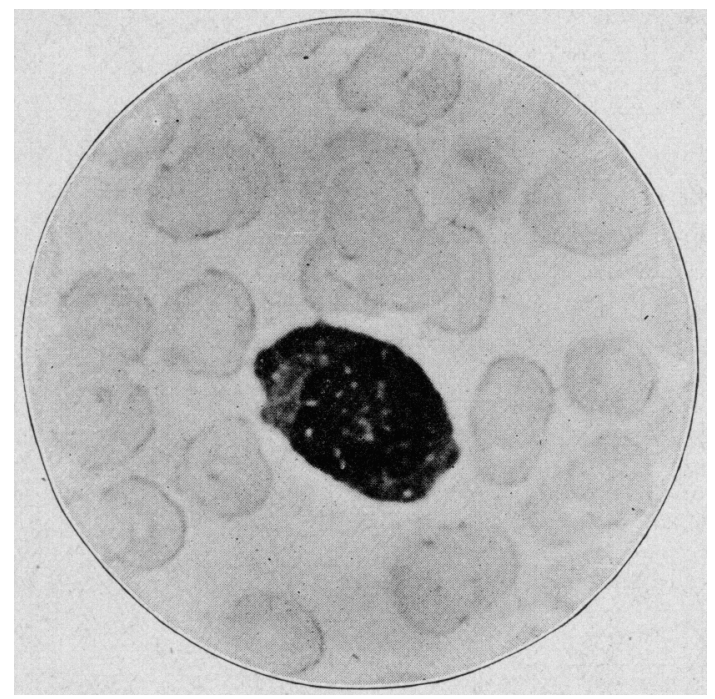

Fig. 2.-Photomicrograph of an individual myelocyte under still higher magnification.

Some of the older theories regarding the distinctive color found in chloroma are those of Balfour, ${ }^{17}$ who believed that the pigment was a bilirubin derivative, and of Dittrich, ${ }^{18}$ who thought it was a premature putrefactive change. Reynolds ${ }^{19}$ thought a combination of fatty acids with iron was the factor. Huber ${ }^{20}$ and Chiari ${ }^{21}$ believed the pigment to be a lipochrome. They stated that they saw fatty greenish granula-

13. Leber: Arch. f. Ophth. 24:295.

14. Wende: Am. J. M. Sc., 1901 , p. 836.

15. Miller: Arch. Path. Inst., Lond. Hosp. 1:1.

16. Paviot and Fayolle: Prov. méd., 1897.

17. Balfour: Edinburgh M. \& S. J. 43:319, 1835.

18. Dittrich: Prag. Vierteljahrsschr. f. d. prakt. Heilk. 2:104, 1846.

19. Pope and Reynolds: Lancet $1: 1351,1907$.

20. Huber: Arch. d. Heilk. 19: 1878.

21. Chiari: Prag. Ztschr. f. Heilk. 4: 1883. 
tions in chloroma tissue, but the majority of writers have not been able to corroborate this. Askanazy ${ }^{22}$ points out the fact that fat is pigmentophil, and thinks that the pigment is merely incorporated in the fat goblets. The parasitic theory has been advanced by Lang, but no one has ever been able to isolate any organisms except such as occasionally are implanted secondarily. Virchow and von Recklinghausen ${ }^{23}$ have attributed the color to the so-called parenchyma color typical of chloromatous tumors, just as we have typical parenchyma colors in the liver, myocardium, etc. The color is presumed to be merely due to the physical effect produced by the molecular structures of the tissues. Askanazy ${ }^{22}$ promulgated the theory that the color in chloroma is analogous to the color found in pus. He has been able to bring out the same color change in pus as in chloroma by treating it with a mixture of formalin and ammonia. He thinks that cells of the myeloid series are necessary for the production of this green color, as the oxidation of lymphocytes gave no green reaction, except in a case of malignant lymphoma which was found to be rich in eosinophils. He also suggests that the less highly differentiated cells frequently found in the rapidly fulminating cases of chloroma are not so apt to produce this change, myelocytes and myeloblasts causing it more distinctly. This was not the experience in our case; in spite of the high percentage of myelocytes and myeloblasts there was nothing to suggest a greenish tinge, but merely a grayish discoloration. None of these theories has been proved, and a great many are not capable of proof, and the subject is still debatable.

22. Askanazy: Internat. Clinics, 1913.

23. Von Recklinghausen: Tageblatt der 58ten Versammlung deutscher Naturforscher und Aerzte in Strassburg, 1885. 